\title{
OS PROBLEMAS DOS ESTUDANTES NA LEITURA DO GÊNERO HISTÓRIA EM QUADRINHOS
}

\author{
Data de recebimento: $16 / 09 / 2018$ \\ Aceite: 25/10/2018 \\ Gabriel Gustavo dos SANTOS (UENP) ${ }^{1}$ \\ Nerynei Meira Carneiro BELLINI (UENP) ${ }^{2}$
}

\begin{abstract}
Resumo: Este artigo tem como finalidade analisar os resultados de um questionário elaborado para avaliar os conhecimentos de uma turma de espanhol em nível de aprimoramento sobre o gênero história em quadrinhos (HQ), além de discutir sobre a importância de utilizar esse tipo de gênero para o ensino de línguas estrangeiras, em nosso caso, o Espanhol. O presente trabalho tem, ainda, o objetivo de apresentar alguns dos elementos constitutivos dos quadrinhos, para exemplificar as dúvidas encontradas nos questionários, e outras que possam vir a surgir. Para tanto, utilizaremos como suporte teórico os estudos de Cagnin (1975), de Paulo Ramos (2016), de Vergueiro e Ramos (2009).

Palavras-chave: História em quadrinhos. Gênero discursivo.

Abstract: The aim of this article is to analyze the results of a questionnaire designed to evaluate the knowledge of a Spanish class at the level of improvement on the genre comics (HQ), and to discuss the importance of using this type of genre for teaching of foreign languages, in our case, Spanish. The present work also aims to present some of the constituent elements of comics, to exemplify the doubts found in the questionnaires, and others that may arise. For that, we will use as theoretical support the studies of Cagnin (1975), Paulo Ramos (2016), Vergueiro and Ramos (2009).
\end{abstract}

Keywords: Comic strip. Discursive gender.

\section{Introdução}

Este trabalho é fruto de um projeto de iniciação científica $\mathrm{PIBIC}^{3}$, realizado em 2016-2017, no estado do Paraná, financiado pela Fundação Araucária. O projeto, inicialmente, foi concebido por outro aluno, no entanto, por não poder continuar a pesquisa, eu entrei em seu lugar. A princípio, a proposta possuía como foco principal o ensinoaprendizagem do idioma Espanhol por meio do gênero história em quadrinhos (HQ), porém, no decorrer de nossa investigação constatamos que os alunos não apresentavam conhecimentos suficientes sobre o gênero em questão para que ele fosse utilizado apenas

\footnotetext{
${ }^{1}$ Graduando em Letras Português-Espanhol, UENP, Andirá-PR, Brasil. gabrielsantosps50@gmail.com

${ }^{2}$ Doutora em Literatura, UENP, Jacarezinho-PR, Brasil. nery@uenp.edu.com

${ }^{3}$ O Programa Institucional de Bolsas de Iniciação Científica (PIBIC) é um programa voltado à iniciação de alunos de graduação à pesquisa científica. Nesse sentido, a pesquisa aqui apresentada buscou transpor os muros da academia e ir até às salas de aula para aplicar os conhecimentos produzidos.
} 
como um meio de se aprender a língua destacada. Por isso, mudamos o foco do projeto para o ensino-aprendizagem da $\mathrm{HQ}^{4}$, contudo, sem deixar de lado a intenção inicial de se trabalhar com a Língua Espanhola, mas agora tendo-a como meio e não mais como finalidade.

Neste artigo, temos o objetivo de apresentar e problematizar as respostas dos alunos a respeito de algumas questões realizadas sobre gênero história em quadrinhos (HQ), sendo esse questionário a etapa correspondente à produção inicial da sequência didática (SD) aplicada em uma turma em nível de aprimoramento do CELEM $^{5}$ de Espanhol, composta por doze alunos, cujas faixas etárias variavam de dez a setenta anos, na cidade de Andirá, no Paraná, em 2017, durante o período vespertino, em seis aulas (com duração de duas horas cada). Antes disso, contextualizaremos alguns aspectos importantes desse gênero e que foram utilizadas nas perguntas. Pretendemos, dessa forma, corroborar para os estudos que primam por um ensino diferente, atraente e, concomitantemente, capaz de atender às necessidades dos alunos.

A importância desse estudo encontra-se no fato de que com a crescente difusão desse gênero, nos mais diversos meios (livros didáticos, provas, internet, jornais), torna-se ainda mais necessário fazer com que o aluno o compreenda em sua totalidade, levando em consideração seus aspectos estruturais, funcionais e sociais. Com isso, procura-se contribuir para a formação de indivíduos capazes de ler e interpretar os textos e o mundo a sua volta.

No entanto, por muito tempo as histórias em quadrinhos ficaram excluídas do ambiente escolar. Essas publicações eram vistas com maus olhos pelos professores. Por se constituírem de dois signos gráficos, a imagem, representada pelo desenho, e a linguagem escrita, como afirma Cagnin (1975) elas eram menosprezadas nas escolas, pois os professores acreditavam tratar-se de uma leitura muito fácil para o aluno e, consequentemente, de menor valor, já que elas possuíam o desenho para auxiliá-lo na compreensão do texto. Além disso, o conteúdo delas também era considerado irrelevante em face dos temas tratados na literatura.

\footnotetext{
${ }^{4}$ De acordo com Ramos (2016), as histórias em quadrinhos podem ser entendidas como um enorme rótulo capaz de abarcar diversos outros gêneros, cada um com características específicas e unidos por alguns aspectos semelhantes, um hipergênero, que funcionaria como um grande guarda-chuva em que se encontrariam as charges, os cartuns, as tiras e diversas outras produções desse tipo. Apesar de o projeto ter trabalhado com todos esses gêneros, neste artigo focalizaremos o trabalho realizado com as tiras cômicas, pelo fato de ser o gênero que mais atraiu os alunos durante as aulas.

${ }^{5}$ O Centro de Línguas Estrangeiras Modernas (CELEM) é um espaço pedagógico criado no ano de 1986 pela Secretaria de Estado da Educação do Paraná - SEED, para ofertar o ensino de línguas estrangeiras aos alunos e professores da rede pública e à comunidade em geral. Ele oferta o ensino de diversos idiomas: Alemão, Espanhol, Francês, Inglês, Italiano, Japonês, Mandarim, Polonês, Ucraniano e Língua Brasileira de Sinais, entretanto, em Andirá, só é ofertado o Espanhol. A duração obrigatória para se obter o diploma é de dois anos, mas existem cursos que oferecem mais um ano de aprimoramento para aqueles que desejarem.
} 
Houve um tempo, não tão distante assim, em que levar revistas em quadrinhos para a sala de aula era motivo de repreensão por parte dos professores. Tais publicações eram interpretadas como leitura de lazer e, por isso, superficiais e com conteúdo aquém do esperado para a realidade do aluno. Dois dos argumentos muito usados é que geravam "preguiça mental", nos estudantes e afastavam os alunos da chamada "boa literatura", (VERGUEIRO; RAMOS, 2009, p. 13).

Essa visão preconceituosa sobre os quadrinhos por parte dos professores e dos pesquisadores era respaldada pelo pouco conhecimento científico que se tinha sobre o tema em questão e imperou no Brasil na segunda metade do século passado, como observam Vergueiro e Ramos (2009). Cagnin (1975) apresenta algumas perspectivas em que os quadrinhos podem ser analisados e que podem nos ajudar a entender a ideia que se tinha sobre esse tipo de texto naquela época. Uma das perspectivas apresentadas por ele é: ' Psicológicas: a leitura dos quadrinhos como higiene mental; tal como distração; o menor dispêndio de energia; a facilidade e, portanto, o menor custo de aprendizagem'” (CAGNIN, 1975, p. 22, grifo do autor). Esse discurso sobre os quadrinhos serem uma leitura de menor valor era amplamente compartilhado pela falta de conhecimentos científicos sobre o assunto na época.

Sua aceitabilidade nas salas de aula ocorreu de forma gradativa. Estudos mais sérios começaram a ser produzidos sobre as histórias em quadrinhos, dentre as diversas obras sobre o assunto, é possível ressaltar Os quadrinhos, uma das obras pioneiras sobre o tema no Brasil, escrita pelo autor Antônio Luiz Cagnin, que foi publicada, pela primeira vez, em 1975, e que até hoje serve de referência para aqueles que estudam sobre o tema e que, neste artigo, é adotada como referencial teórico. Com o crescente fluxo de pesquisas científicas advém um maior esclarecimento sobre o assunto e estímulos para que houvesse mais discussões nos meios acadêmicos.

Com isso, em 1980 já era possível encontrar as histórias em quadrinhos nos livros didáticos, o que denota um significativo avanço, já que até há pouco tempo elas estavam completamente banidas das escolas, como pudemos observar. Porém, uma evolução mais substancial só pôde ser observada uma década depois, com a Lei de Diretrizes e Bases (LDB), em 1996. Na qual, é apontada a necessidade da incorporação de mais linguagens e manifestações artísticas no ensino básico. (VERGUEIRO; RAMOS, 2009).

Outro fato que contribuiu para a inserção dos quadrinhos nas escolas foi a inclusão deles nos Parâmetros Curriculares Nacionais (PCN), os quais mencionam a necessidade de 
serem trabalhados diferentes tipos de gêneros textuais no ensino básico, dentre eles, os quadrinhos.

O Programa Nacional Biblioteca da Escola (PNBE) também foi um importante instrumento para que as histórias em quadrinhos fossem levadas às escolas. Esse projeto, cuja finalidade é a compra e a distribuição de obras para as escolas públicas contribuiu para a inclusão dos quadrinhos nos sistemas de ensino. Entretanto, como salienta Vergueiro e Ramos (2009), ainda é grande a discrepância entre o número de obras literárias, e o número de obras de quadrinhos nas bibliotecas das escolas brasileiras. Ainda existe uma visão de que esse tipo de texto serve apenas para o entretenimento e que pouco tem a contribuir, de forma construtiva, na formação do estudante. Isso pode ser observado por meio da hierarquia dos gêneros textuais nas escolas, na qual, os livros de literatura ficam, muito acima, em relação à quantidade, das obras de quadrinhos, como é facilmente observável na maioria das bibliotecas das escolas do Brasil.

Como pode ser verificada, a jornada para que as histórias em quadrinhos chegassem até às escolas foi paulatina e ainda hoje enfrenta alguns problemas. As histórias em quadrinhos constam nos textos mais importantes que norteiam a educação brasileira, tornando sua utilização em sala de aula totalmente legítima e de extrema importância, sendo, atualmente, amplamente divulgadas em livros didáticos e provas realizadas pelo governo. Com isso, há a necessidade de que haja, cada vez mais, estudos científicos abordando esse tema que ainda encontra algumas dificuldades de entendimento por muitos. É nesse sentido que segue o nosso trabalho.

\section{Os quadrinhos: um conceito amplo}

Segundo Cagnin (1975), as histórias em quadrinhos possuem diferentes nomes ao redor do mundo, nos Estados Unidos é chamada de Comics, na França é chamada de Bandes Dessinées, na Itália é conhecida como Fumetti, na Espanha lhe é atribuído o nome de Tebeo, na América Espanhola é conhecida por Historieta, já em Portugal, Historias aos quadrinhos e, no Brasil, história em quadrinhos, e Gibi para se referir às revistas que as veicula. Essa palavra teve origem de uma revista brasileira criada na década de quarenta que se chamava Gibi. Independente dos nomes que são atribuídas às HQs, todos eles se referem a uma mesma coisa: uma forma narrativa feita de imagens fixas (CAGNIN, 1975). 
$\mathrm{O}$ autor nos orienta que a leitura dos quadrinhos deve seguir algumas regras para ser realizada de forma satisfatória. Primeiramente deve-se levar em conta a ordem em que os balões, e as legendas, caso houver, estão dispostos, essa ordem indicará a sequência cronológica da ação, orientando o leitor. Os quadrinhos devem ser lidos horizontalmente, da esquerda, para a direita, de forma que as tiras superiores precedam as inferiores (CAGNIN, 1975, p. 53).

Segundo Paulo Ramos (2016), os quadrinhos possuem uma linguagem autônoma, mesmo que possuam características semelhantes a outros gêneros ${ }^{6}$. Essa relação de semelhança, no entanto, não os torna derivação de outros gêneros mais prestigiados socialmente. Sobre essa questão o autor disserta que:

Quadrinhos são quadrinhos. E, como tais, gozam de uma linguagem autônoma, que usa mecanismos próprios para representar os elementos narrativos. Há muitos pontos comuns com a literatura, evidentemente. Assim como há também com o cinema, o teatro e tantas outras linguagens (RAMOS, 2016, p. 17).

O mesmo autor define as histórias em quadrinhos como um grande rótulo capaz de abarcar uma grande variedade de outros gêneros unidos por algumas semelhanças e diferenciados por algumas especificidades próprias. Ele utiliza o termo hipergênero, usado primeiramente por Maingueneau, para se referir a esse grande rótulo, de modo que nós, também, adotaremos esse termo para nos referirmos aos quadrinhos em certas situações. Sobre a diversidade de gêneros, o autor afirma: "Podem ser abrigados dentro desse grande guarda-chuva chamado quadrinhos os cartuns, as charges, as tiras cômicas, as tiras cômicas seriadas, as tiras seriadas e os vários modos de produção das histórias em quadrinhos" (RAMOS, 2016, p. 21, grifo do autor). Apresentaremos algumas rápidas classificações feitas sobre alguns desses gêneros para uma melhor compreensão da variedade que comporta os quadrinhos.

A charge, segundo Ramos (2016), é um gênero que tem como finalidade o humor, e para isso recria algum fato noticiado visando essa finalidade. Para um entendimento total deste gênero é necessário que o leitor dê ênfase no conhecimento enciclopédico ${ }^{7}$, uma vez que, geralmente, os temas abordados por esse gênero são notícias e, para que o leitor possa compreender, necessita ter um prévio conhecimento do conteúdo que está sendo abordado.

\footnotetext{
${ }^{6}$ A noção de gênero utilizada nesse artigo é referente ao conceito de gêneros do discurso proposto por Bakhtin (2003).

${ }^{7}$ Conceito utilizado por Mônica Cavalcante (2013), diz respeito ao conhecimento de mundo que cada leitor possui e é com ele, e com a ajuda de outros, que é possível o leitor atribuir sentido ao texto.
} 
Além desse conhecimento, é preciso utilizar o conhecimento interacionista ${ }^{8}$, para saber que as charges são, geralmente, veiculadas aos noticiários e é essa a característica primordial que a difere de outro gênero: o cartum.

O cartum, geralmente, retrata situações corriqueiras, do cotidiano, e é daí que o humor é extraído, ele e a charge são muito parecidos e o elemento distintivo entre os dois reside no fato de que o primeiro não retrata assuntos dos noticiários, diferente do segundo (RAMOS, 2016).

O formato das tiras cômicas foi tão fortemente incorporado ao nome que elas também são conhecidas apenas por tiras. Sua característica mais marcante é o humor, mas existem outras; elas são curtas, construídas em um ou mais quadrinhos, com personagens fixos ou não, e é apresentada uma situação inesperada ao final da tira (RAMOS, 2016). Já as tiras seriadas são histórias narradas em partes. Cada tira funciona como um capítulo que faz parte de uma trama maior, como nas telenovelas. Para entendermos essas tiras temos que acompanhar sua sequência cronológica de criação. As tiras cômicas seriadas são um híbrido de tira cômica e tira seriada. Trata-se de um gênero que carrega as características de ambas: da primeira, o desfecho inesperado, e da segunda, a divisão em capítulos (RAMOS, 2016).

As caricaturas podem ser consideradas um tipo de charge que não apresenta história alguma, apenas recria uma figura de forma engraçada ou irônica: "Entre eles surgem aqueles que não contam história nenhuma, somente apresentam algo engraçado ou irônico: a caricatura'” (CAGNIN, 1975, p. 179).

Sobre a diversidade de nomenclaturas, Ramos (2016, p. 16) observa:

Muitas vezes, esse excesso de nomes é consequência de um desconhecimento das características das histórias em quadrinhos e de seus diferentes gêneros. Sem saber direito do que se trata, escolhe-se um termo provisório e sem muito critério. Do ponto de vista do leitor, essa pluralidade de rótulos pode até atrapalhar a leitura.

Por isso faz-se necessário uma classificação precisa sobre os diversos gêneros que compõem as histórias em quadrinhos, para que o leitor, ao lê-los, tenha em mente suas principais características e saiba fazer a diferenciação entre eles. Cada gênero é veiculado a uma esfera social e possui características que atendem às necessidades particulares dessa esfera (BAKHTIN, 2003), por isso é fundamental que o leitor saiba das especificidades de cada gênero que os quadrinhos abarcam.

\footnotetext{
${ }^{8}$ Conceito também utilizado por Mônica Cavalcante (2013), e refere-se ao conhecimento das especificidades de cada gênero, desde como é estruturado até onde circulam.
} 
Outro aspecto importante é o desenho, que carrega em si próprio o estilo daquele que o desenha, seu autor. É possível observar uma infinidade de traços diferentes ao se comparar vários quadrinhos de autores diferentes, sendo possível até identificá-los pelas características próprias de seus traços. O autor informa que não é possível ter uma classificação científica precisa em relação aos traços, pelo fato de haver uma grande variedade que depende, exclusivamente, da criatividade do artista. Porém, Cagnin (1975) consegue distinguir três tipos diferentes de traços. Os realistas, que retratam da forma mais fiel possível, as figuras que pretende recriar. Os estilizados, que, apesar de recriar as figuras de forma realista, apresentam características mais marcadas, como o próprio nome diz, estilizadas pelo próprio desenhista. E, por fim, os traços caricatos, que apesar de representar as coisas do mundo têm sua imagem reformulada para agregar um sentido ao texto, geralmente esse tipo de traço visa produzir um sentido de humor.

Outra característica dos quadrinhos é a legenda, que é usada para auxiliar o criador do quadrinho na narração, sua função é narrar o que está acontecendo ou relembrar o que já aconteceu (CAGNIN, 1975). Ela, geralmente, por ser comumente pequena, ocupa as extremidades dos quadrinhos, mas pode, naturalmente, ser encontrada de outras formas.

Outro elemento importante nos quadrinhos é o título, que de acordo com Cagnin (1975), pode variar em duas formas: a fixa e as variáveis. A forma fixa funciona como uma espécie de marca registrada e, por ser fixa, não influi no desenrolar da história, apenas diferencia uma história das outras. Como exemplos de forma fixa, podemos citar: Batman e Robin, A Turma da Mônica, Horácio etc. Já as formas variáveis funcionam como um resumo da história que o leitor irá ler, seu título dependerá do que irá tratar a história.

Nem sempre a história em quadrinho irá possuir um texto escrito, e nesse caso, sua interpretação será pautada, exclusivamente, pelo desenho. É o caso da caricatura, em que não é preciso que o autor incorpore uma mensagem escrita para atingir o sentido que pretende geralmente o humor - esse sentido é conseguido simplesmente por meio do desenho. Isso não acontece apenas com as caricaturas, tiras inteiras podem ser criadas sem o texto verbal escrito. Dependerá se o sentido que o desenhista visa passar com o quadrinho obtém-se apenas pelo desenho.

Optamos por trazer essas breves explicações sobre alguns dos diversos elementos constituintes das histórias em quadrinhos, pelo fato de crermos que seja necessário elucidar algumas questões que nos parecem de extrema importância na leitura dos quadrinhos, além de 
acreditarmos que a compreensão de cada elemento ajuda na compreensão do todo, tornando a leitura mais rica e produtiva.

\section{Os diversos tipos de balões}

O balão tornou-se um traço distintivo das histórias em quadrinhos, dentre suas características mais marcantes estão sua rica diversidade de formas e sua adaptação aos contextos retratados nas histórias. Nesta mesma perspectiva Cagnin (p. 120-121) afirma:

As formas dos balões são diversíssimas. A mais comum é a que se aproxima de um círculo. Um apêndice em forma de flecha está voltado para a boca da figura que fala. Este círculo envolve a fala. Assim, o balão é o elemento que indica o diálogo entre as personagens e introduz o discurso direto na sequência narrativa. Além de desenvolverem esta função precípua, participam também da imagem. Disto decorrem dois fatos importantes: como imagem, ele compõe o quadro justamente com as figuras, e, com elas, segue uma disposição estética, formando um todo. Enquanto elemento da fala, traz em si dados, informações das qualidades desta fala (metalinguísticas, portanto).

De acordo com o autor, os balões possuem duas formas básicas: o balão fala e o balão pensamento. Enquanto um representa o diálogo entre as personagens, o outro é uma informação exclusiva do leitor, que consegue ler os pensamentos das personagens. Esses dois tipos básicos de balões foram convencionados pelos próprios quadrinhos e adotados por todos os desenhistas, mesmo que não sejam usados em sua forma original, servem de base para a criação de novos balões (CAGNIN, 1975).

O balão fala tem um contorno nítido e contínuo e o apêndice em forma de seta sai da boca do falante. Já balão pensamento tem a linha irregular, ondulada, com formato de nuvem e o apêndice é formado por pequenas bolhas ou nuvens que saem da cabeça do pensante. Sendo possível, a partir dessas duas formas básicas, uma infinidade de variações delas. Citaremos algumas formas de balões que carregam sentidos especiais em determinados contextos:

O balão-cochicho é usado quando o personagem quer falar baixo para não ser ouvido por um terceiro e é representado por uma linha de contorno pontilhada. Em contrapartida, quando o personagem deseja gritar é utilizado o balão-berro, que tem as extremidades voltadas para fora como uma explosão. Também existe o balão que engloba a fala de vários personagens em uma só, e a esse balão é atribuído o nome de balão-uníssono. Há, também, os balões dois em um, que são unidos um no outro, e são chamados de balões-duplos, o intervalo 
de um balão para o outro informa que a fala foi dividida por um breve silêncio. Pode aparecer, em alguns casos, quadrinhos em que não há balão algum, nesse caso, saberemos quem está falando ou pensando, pois haverá um traço ligando o personagem à ação (CAGNIN, 1975).

Ramos (2016) cita algumas outras formas que os balões podem ser encontrados. O balão-trêmulo é representado por linhas tortas e sugere medo ou uma voz tenebrosa. O balão de linhas quebradas indica a fala de aparelhos eletrônicos. O balão-vibrado indica voz tremida. O balão-glacial indica desprezo ou choro. Os balões-intercalados indicam, durante a leitura, que pode haver outro balão com a fala de um interlocutor. O balão-mudo não contém fala, apenas sinais gráficos, geralmente, pontos. O balão-sonho indica o sonho do personagem. O balão de apêndice cortado indica a voz/ação de um personagem que não aparece no quadrinho. E os balões-especiais, assumem a forma da emoção que o personagem está sentindo.

Apesar dessas classificações, não é possível precisamente dizer quantos tipos de balões há, uma vez que eles dependem exclusivamente da imaginação de cada autor para serem criados. Ramos observa:

Robert Benayoun, em Le Ballon dans la Bande Dessinée, elenca 72 formas distintas de balão. É bem provável que o número esteja defasado. À época do levantamento, não havia a presença do computador. As histórias em quadrinhos, hoje, contam com inesgotáveis recursos de informática para serem produzidas. Isso permite, por exemplo, a criação de balões personalizados para cada personagem (RAMOS, 2016, p. 42, grifos do autor).

\section{As dificuldades dos alunos frente às histórias em quadrinhos}

Apresentaremos, a seguir, os dados dos questionários aplicados em uma turma de Espanhol do CELEM, de doze alunos, em nível de aprimoramento, no ano de 2017, na cidade de Andirá, e algumas breves observações sobre os resultados. Em uma sequência didática ${ }^{9}$, a primeira produção consiste em os alunos tentarem produzir, pela primeira vez, seu próprio texto do gênero que está sendo trabalhado e, desse modo, revelarem para si mesmos, e para o professor, a ideia que possui dessa atividade. Nesse caso, por esse gênero ser muito complexo

\footnotetext{
${ }^{9}$ Ela se caracteriza por ser um conjunto de atividades realizadas no âmbito escolar, de forma sistematizada, para o ensino-aprendizagem de um determinado gênero (oral ou escrito) realizado por meio de módulos que tem a finalidade de [...] ajudar o aluno a dominar melhor um gênero de texto, permitindo-lhe, assim, escrever ou falar de uma maneira mais adequada numa dada situação de comunicação. (DOLZ; NOVERRAZ; SCHNEUWLY, 2004, p. 83, grifo dos autores). A sequência didática possui a seguinte estrutura: apresentação da situação; produção inicial; os módulos; produção final e reescrita.
} 
para uma produção inicial, por envolver diversas características estruturais que ajudam a dar sentido ao texto como um todo (DOLZ; NOVERRAZ; SCHNEUWLY, 2004). Nesse caminho, o questionário em questão foi desenvolvido para suprir esta importante etapa, justamente, para observar quais as dificuldades que os alunos possuem na leitura e na interpretação das histórias em quadrinhos, e avaliar os conhecimentos deles em relação a elas. Para isso, pedimos que os alunos analisassem a seguinte tira cômica da personagem Mafalda, criada pelo argentino Quino:

Figura 5 - Tirinha cômica da Mafalda
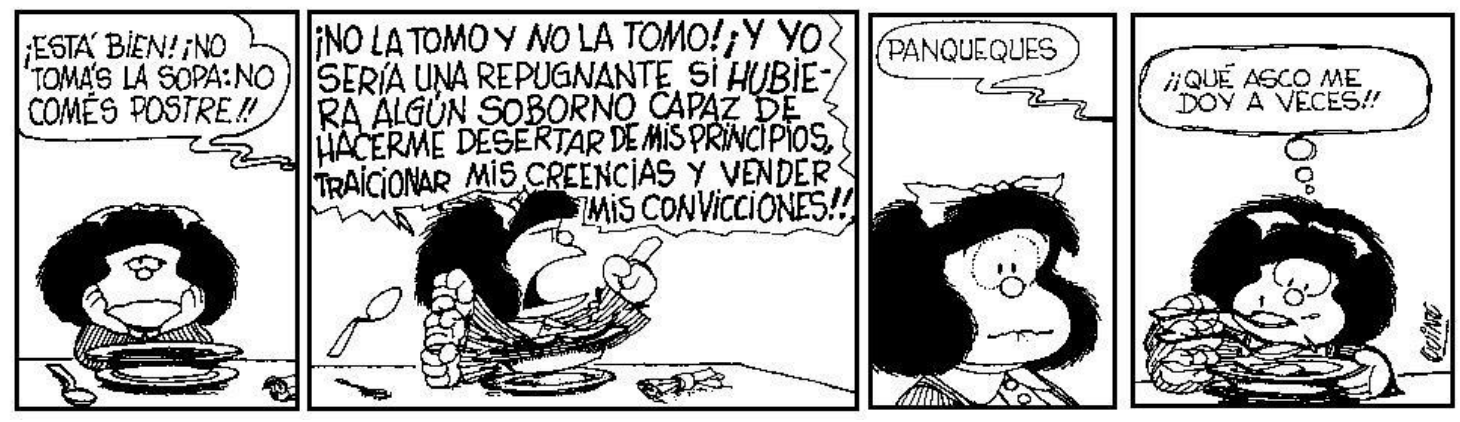

Fonte: Revista Esfinge ${ }^{10}$

Tabela 1 - Questionário aplicado em uma turma de Espanhol em Andirá - março de 2017.

\begin{tabular}{c|c}
\hline $\begin{array}{c}\text { Número de alunos que tiveram } \\
\text { dificuldades na leitura }\end{array}$ & $\begin{array}{c}\text { Número de alunos que não } \\
\text { tiveram dificuldades na leitura }\end{array}$ \\
\hline 5 & 7
\end{tabular}

Fonte: dados da pesquisa.

O maior problema relatado pelos alunos que tiveram dificuldades na leitura da história em quadrinhos foi em relação ao vocabulário. Alguns, por não conseguirem compreender o que estava escrito, pautaram suas análises apenas no desenho e, mesmo aqueles que disseram que não tiveram nenhuma dificuldade na leitura, ao pedirmos que narrassem o que se passava na tira, não conseguiram fazê-lo de maneira razoável, como poderemos ver na tabela abaixo.

Tabela 2 - Questionário aplicado em uma turma de Espanhol em

Andirá - março de 2017.

10 Disponível em <https://www.revistaesfinge.com/filosofia/humor-filosofico/item/1171-mafalda-la-pequenafilosofa-2-parte> Acesso em abril de 2017. 


\begin{tabular}{c|c}
\hline $\begin{array}{c}\text { Número de alunos que } \\
\text { interpretaram a tira de forma } \\
\text { satisfatória }\end{array}$ & $\begin{array}{c}\text { Número de alunos que não } \\
\text { interpretaram a tira de forma } \\
\text { satisfatória }\end{array}$ \\
\hline 2 & 10 \\
\hline
\end{tabular}

Fonte: dados da pesquisa.

Houve uma grande dificuldade por parte dos alunos em entenderem do que se tratava a tira, eles não conseguiram captar a essência dela, isto se deve, em parte, como já mencionado, pelo fato de que muitos não conseguiram interpretar a parte escrita, apoiando, assim, suas interpretações em apenas um dos elementos que constitui a tira: o desenho. Deixando de lado outro elemento primordial para o entendimento do todo: a parte escrita. $\mathrm{O}$ mesmo ocorreu quando pedimos para que eles identificassem o humor na tira, apenas dois conseguiram fazê-lo de maneira satisfatória.

Tabela 3 - Questionário aplicado em uma turma de Espanhol em

Andirá - março de 2017.

\begin{tabular}{c|c}
\hline $\begin{array}{c}\text { Número de alunos que acharam } \\
\text { a leitura fácil }\end{array}$ & $\begin{array}{c}\text { Número de alunos que acharam } \\
\text { a leitura mediana }\end{array}$ \\
\hline 7 & 5 \\
\hline
\end{tabular}

Fonte: dados da pesquisa.

Curiosamente, a maioria dos alunos classificou a leitura da tira como fácil. Entretanto, como já foi possível observar, a maioria não conseguiu compreender a tira, fizeram apenas uma leitura parcial ao analisarem apenas o desenho, tornando a leitura, dessa forma, superficial. Algumas reflexões que nos é permitida diante desta problemática seria a de pensarmos: E caso tirássemos o desenho e deixássemos apenas a parte escrita, os alunos ainda teriam a mesma concepção de que se trata de uma leitura fácil? Teriam uma compreensão melhor ou pior? Até que ponto o aluno se apoia no desenho para interpretar a história como um todo? Estas são perguntas que não daremos conta de responder nesse artigo, mas que podem vir a ser alvo de análises em trabalhos futuros.

Tabela 4 - Questionário aplicado em uma turma de

Espanhol em Andirá - março de 2017.

\begin{tabular}{cc}
\hline $\begin{array}{c}\text { Número de alunos que já } \\
\text { leram HQ em português }\end{array}$ & $\begin{array}{c}\text { Número de alunos que já } \\
\text { leram HQ em espanhol }\end{array}$ \\
\hline 12 & 0 \\
\hline \multicolumn{2}{l}{ Fonte: dados da pesquisa. }
\end{tabular}


Esse dado é bastante esclarecedor e talvez possa nos ajudar a entender as dificuldades de interpretação que os alunos tiveram ao ler a tira cômica em língua espanhola. Por nunca terem lido uma tira em espanhol antes, possa ser que as dificuldades para a interpretação tenham sido maiores, no entanto, apenas esse fato não dá conta de explicar totalmente os problemas de compreensão dos alunos. As respostas que eles deram revelam, infelizmente, que os quadrinhos são pouco utilizados no ensino de língua estrangeira, em nosso caso, o espanhol.

Apesar de não ser o foco de nossa pesquisa, analisamos um livro didático de ensino de língua espanhola, Enlaces: para jovénes brasileños (2013), sem qualquer embasamento científico, apenas por curiosidade, para observar com que frequência os quadrinhos apareciam no livro, constatamos pouquíssimos casos em que eles apareceram, sete vezes para sermos exatos. Isso denota que, lamentavelmente, as histórias em quadrinhos ainda encontram dificuldade na sua inserção nas salas de aula, tanto por parte dos professores, que não sabem como trabalhar com esse gênero, como também por parte dos materiais de conteúdos escassos. Um fato interessante é que, daqueles que afirmaram já terem lido alguma HQ em português, todos citaram a obra de Maurício de Souza, mais especificamente, A Turma da Mônica.

\begin{tabular}{|c|c|}
\hline \multicolumn{2}{|c|}{ Andirá - março de 2017.} \\
\hline $\begin{array}{c}\text { Número de alunos que gostam } \\
\text { de ler HQs }\end{array}$ & $\begin{array}{l}\text { Número de alunos que não } \\
\text { gostam de ler HQs }\end{array}$ \\
\hline 10 & 2 \\
\hline
\end{tabular}

Fonte: dados da pesquisa.

Como é possível observarmos, com base nas respostas dos alunos, a leitura das histórias em quadrinhos é prazerosa para a maioria deles. Entre as respostas sobre o porquê deles gostarem de ler esse gênero estão: porque elas são engraçadas, porque a leitura é mais fácil, porque elas possuem desenho etc. Já aqueles que responderam que não gostam de ler histórias em quadrinhos, justificam-se afirmando que não gostam de ler qualquer tipo de texto. Isso mostra uma grande aceitabilidade dos quadrinhos por parte dos alunos, que apreciam esse gênero. Esses dados mostram que os alunos têm interesse nas histórias em quadrinhos, por isso é preciso que os professores tenham um conhecimento mais aprofundado 
ao abordarem esse hipergênero, para que possam ensiná-lo da melhor forma, de modo a abarcar a maior quantidade possível de seus aspectos constituintes. Quando questionados se gostariam de aprender espanhol por meio das histórias em quadrinhos todos responderam de forma afirmativa, ratificando o que já foi exposto, a necessidade de ensinar, da melhor forma possível, com o auxílio delas.

Tabela 6 - Questionário aplicado em uma turma de Espanhol em Andirá - março de 2017.

\begin{tabular}{c|c}
\hline $\begin{array}{c}\text { Número de alunos que } \\
\text { citaram jornais, revistas e } \\
\text { internet como meios em } \\
\text { que as HQs circulam }\end{array}$ & $\begin{array}{c}\text { Número de alunos que não } \\
\text { conseguiram responder }\end{array}$ \\
\hline \multicolumn{2}{c}{4} \\
\hline
\end{tabular}

Fonte: dados da pesquisa.

Esses dados mostram a falta de conhecimento dos alunos sobre onde as histórias em quadrinhos circulam. Saber disso é de extrema importância para podermos entender melhor com que finalidade o texto foi produzido. Em cada esfera social o gênero possui características e finalidades próprias para satisfazer o meio em que circula (BAKHTIN, 2003), o mesmo ocorre com as histórias em quadrinhos, cujas características e finalidades variam de acordo com as especificidades de seu gênero e do meio em que atuará.

Tabela 7 - Questionário aplicado em uma turma de Espanhol em Andirá - março de 2017.

\begin{tabular}{c|c}
\hline $\begin{array}{c}\text { Número de alunos que } \\
\text { souberam descrever as } \\
\text { diferenças entre a charge, o } \\
\text { cartum e a tira. }\end{array}$ & $\begin{array}{c}\text { Número de alunos que não } \\
\text { souberam descrever as } \\
\text { diferenças entre a charge, o } \\
\text { cartum e a tira. }\end{array}$ \\
\hline 0 & 12 \\
\hline Fonte: dados da pesquisa.
\end{tabular}

Esse dado demonstra o que vimos anteriormente, que os leitores não conhecem os diversos tipos de gêneros que os quadrinhos comportam e tratam-nos como se fossem a mesma coisa. Além do fato de que a grande variedade de nomes dificulta a diferenciação dos gêneros por parte do leitor como já observado por Ramos (2016).

Tabela 7 - Questionário aplicado em uma turma de 
Espanhol em Andirá - março de 2017.

\begin{tabular}{c|c}
\hline $\begin{array}{c}\text { Número de alunos que } \\
\text { souberam explicar sobre } \\
\text { os diversos tipos de balões }\end{array}$ & $\begin{array}{c}\text { Número de alunos que não } \\
\text { souberam explicar sobre } \\
\text { os diversos tipos de balões }\end{array}$ \\
\hline 2 & 10
\end{tabular}

Fonte: dados da pesquisa.

Apenas dois, dos doze alunos, conseguiram explicar de forma satisfatória o porquê de os balões adquirirem diferentes formas em diferentes situações. Essa diversidade de formas é uma das características mais marcantes dos quadrinhos. Saber sobre a diferença entre os balões pode ajudar o leitor a entender o que está sendo exposto; caso o personagem esteja estressado, será utilizado, provavelmente, o balão-berro para expressar sua fala; já se o personagem não quer ser ouvido por terceiros, o desenhista provavelmente usará o balãocochicho, e assim por diante. Saber dessas diferenças pode tornar a leitura mais rica e produtiva e, até mesmo, nos ajudar a compreender melhor o texto como um todo dotado de sentido.

Tabela 8 - Questionário aplicado em uma turma de Espanhol

\begin{tabular}{c|c}
\multicolumn{2}{c}{ em Andirá - março de 2017.} \\
\hline $\begin{array}{c}\text { Número de alunos que } \\
\text { sabiam o que era uma } \\
\text { onomatopeia }\end{array}$ & $\begin{array}{c}\text { Número de alunos que não } \\
\text { sabiam o que era uma } \\
\text { onomatopeia }\end{array}$ \\
\hline 3 & 10 \\
\hline
\end{tabular}

Fonte: dados da pesquisa.

As onomatopeias, assim como a diversidade de balões, também são uma das características mais marcantes dos quadrinhos, servindo como recurso para expressar sons na forma escrita. A maioria dos alunos, infelizmente, não conseguiu explicar o que seria uma onomatopeia, mas é muito provável que eles já tenham entrado em contato com ela, uma vez que a mesma é muito utilizada nas histórias em quadrinhos. A dificuldade, neste caso, é mais fácil de ser contornada, de modo que o problema reside no fato deles não saberem o nome que leva essa representação do som e que com uma leitura mais crítica dos quadrinhos já seria possível contorná-la.

Os dados colhidos dos questionários nos oferecem um rico material para podermos avaliar as dificuldades dos alunos frente aos quadrinhos e, assim, podermos elaborar uma sequência didática que atenda as necessidades dos mesmos, procurando proporcionar a eles um conhecimento maior sobre esse hipergênero. 


\section{Considerações finais}

Como exposto anteriormente, os quadrinhos já começaram a ser introduzidos nos ambientes escolares; constam na grande maioria dos livros didáticos, nos exames nacionais mais importantes produzidos pelo governo e nos documentos norteadores da educação brasileira. Apesar disso, eles ainda encontram dificuldades na sua utilização em sala de aula.

Isso pode ser observado pela falta de conhecimento dos alunos sobre esse hipergênero, mesmo eles já tendo, possivelmente, entrado em contato com ele na escola. Esse fato nos leva a outro: a falta de conhecimento do próprio professor sobre os quadrinhos. Esse fato pode ser explicado, em parte, pela má herança deixada para nós, que é a ideia que esse tipo de gênero é inferior a outros mais prestigiados. Por conta disso, muitos professores não se interessam em apreender mais sobre os quadrinhos, já que partilham da concepção de que esse tipo de leitura é de menor prestígio, '... como higiene mental; como distração; o menor dispêndio de energia..." (CAGNIN, 1975, p. 22), consequentemente, na visão deles, não é necessário um estudo mais aprofundado.

Em contraponto a essa perspectiva, está o visível interesse dos alunos em aprender mais sobre, e com, os quadrinhos. Isso fica evidente quando analisamos as respostas deles, em que todos afirmaram achar interessante estudar alguns aspectos da língua espanhola por intermédio dos quadrinhos. Como já mencionado, os quadrinhos não são uma boa ferramenta apenas para o ensino de línguas, mas para o ensino de diversas outras matérias e assuntos.

Para que haja um real aproveitamento dos quadrinhos em sala de aula, é necessário que o professor analise-o como um todo, e que tenha em mente que cada um de seus elementos constitutivos contribui para dar sentido ao todo, dessa forma, quando ele trabalhar com esse gênero é imprescindível que exponha esses elementos aos alunos, a fim de ampliar seus conhecimentos e ajudá-los em uma compreensão maior sobre os quadrinhos.

Concluímos, portanto, que, para que um estudo mais sério e aprofundado seja levado às salas de aula, é preciso que os professores procurem uma compreensão mais aprofundada sobre o assunto e levem esse conhecimento adquirido aos alunos. Uma boa forma de fazê-lo é planejar sequências didáticas (SD) para o ensino do hipergênero em questão e com base nas dificuldades apresentadas pelos alunos, em uma avaliação diagnóstica, trabalhar para a elucidação das dúvidas e dificuldades que possam ser encontradas. 


\section{Referências}

BAKHTIN, Mikhail. Estética da criação verbal. 4. ed. São Paulo: Martins Fontes, 2003. BECHARA, Evanildo. Gramática da língua portuguesa. 2. ed. Rio de Janeiro: Nova Fronteira, 2010.

CAGNIN, Antônio Luiz. Os quadrinhos. São Paulo: Ática, 1975.

CAVALCANTE, Mônica Magalhães. Os sentidos do texto. São Paulo: Contexto, 2013.

OSMAN, Soraia et al. Enlaces: español para jóvenes brasileños. 3. ed. São Paulo: Macmillan, 2013.

RAMOS, Paulo. A leitura dos quadrinhos. 2. ed. São Paulo: Contexto, 2016.

SCHNEUWLY, Bernard; DOLZ, Joaquim. Gêneros orais e escritos na escola. Campinas, SP: Mercado de Letras, 2004. 